\author{
I J M I \\ International Journal of Machine Intelligence \\ ISSN: 0975-2927 \& E-ISSN: 0975-9166, Volume 3, Issue 5, 2011, pp-390-395 \\ Available online at http://www.bioinfo.in/contents.php?id=31
}

\title{
DEVELOPMENT OF NON-DESTRUCTIVE DEVICE FOR DETERMINATION OF ALKALOID LEVEL IN DIOSCOREA HISPIDA
}

\author{
MOHD HUDZARI HJ RAZALI ${ }^{1}$, SYAZILI ROSLAN' ${ }^{1}$ AND KAMARUL 'AIN MUSTAFA2, \\ 1Department of Agriculture Science, Faculty of Agriculture and Biotechnology, 2Faculty of Food Technology, University Sultan \\ Zainal Abidin, 21300, Kuala Terengganu, Terengganu, Malaysia \\ *Corresponding Author: Email- mohdhudzari@unisza.edu.my
}

Received: September 29, 2011; Accepted: October 12, 2011

\begin{abstract}
This study introduced the potential of microwave application in the determination of alkaloid in Dioscorea hispida rhizome. This microwave device is used to measure the coefficient permitivity of microwave level at rhizome surface using mechanical probe. With the same rhizomes, 40 grams was selected for chemical analysis at a laboratory for the programme of East Coastal Economic Regions - Kementerian Pengajan Tinggi, Universiti Sultan Zainal Abidin, Malaysia (ECER-KPT UniSZA). The sample were selected from 12 portion of 2 plants (I and B) collected from Kampung Kudat, Ajil, Terengganu, Malaysia. The result show that the correlation between microwave level and weight of alkaloid with regression, $R^{2}$ is $>0.8$ is acceptable. Using SPSS, the ANOVA value shows significant correlation between microwave level and weight of alkaloid $>0.05$. This work is grouped as nondestructive method to detect the dioscorine which is one of the alkaloid components in the rhizome.
\end{abstract}

Keyword: alkaloid of dioscorea, rapid detection device, alkaloid detection, Dioscorea hispida, microwave sensor

\section{INTRODUCTION}

Dioscorea hispida is a poisonous plant where scientific study have shown that its rhizome contains toxic alkaloid constituents, dioscorine.. The rhizomes can only be consumed after the poisonous dioscorine is removed. This plant is commonly found in secondary forest and grows under shaded areas or near streams. D.hispida is one of the Dioscorea (Yam) species and characterized as a climbing plants with glabrous leaves and twinning stems, which helix readily around take??. D.hispida is one of the most economically important yam species, which serves as a staple food for millions of people in tropical and subtropical countries (Hanh [3]; Udensi [10]) and the only species of which most of the leaves have 3 leaflets and have no aerial rhizomes (Jill and Linda [5]). This plant is classified as a wild creeping and climbing plant which can grow up to 20 meters in height (Sharifah [9]). Traditionally, the stem of D.hispida has been used to treat sinus. The rhizomes has been reported to be rich in essential dietary nutrients (Bhandari et al [7]). This plant is also known by the local with names such as Tuba Ubi, Ubi Nasi, Ubi Cerok, Ubi Kendudok and Ubi Kipas (Nashriyah et al [8]). Figure 1 shows the rhizome of D.hispida. Hudzari et al., (2011) mentioned that the advancement of technology should be introduced for agriculture research in $D$. hispida within the area of harvesting process, dioscorine removal and dioscorine detection devices [4].

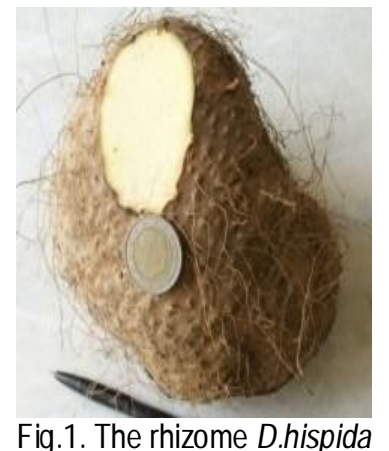

\section{OBJECTIVE}

The objectives of this study are

1) To investigate the alkaloid from the different variety of D.hispida.

2) To determine the level of alkaloid using the microwave sensor.

3) To investigate the relationship between the levels of alkaloid with the microwave signal of $D$.hispida.

4) To develop the simulation model based on alkaloid. 


\section{MATERIALS AND METHOD}

Two plants of $D$.hispida named as plant $A$ and plant $B$, were collected from Kampung Kudat, Ajil, Terengganu, Malaysia. There were three levels for each plant. Three rhizomes were chosen from each level. Figure 2 shows the way the rhizome were chosen.

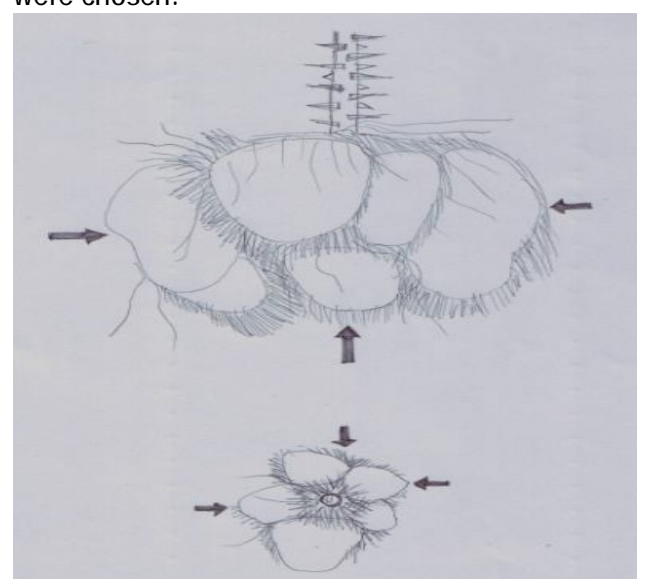

Fig.2- The way to choose the rhizome.

\subsection{Measurement of microwave of $d . h$}

The experimental set up for measuring the magnitude of reflection coefficient, (|S11|) of a monopole antenna includes a monopole antenna as a mechanical sensor probe and an Agilent FieldFox network analyzer as shown in Figure 3. The operating frequency to measure the reflection coefficient was set from $2 \mathrm{MHz}$ to $4 \mathrm{GHz}$. The antenna was inserted into the flesh of the D.hispida rhizome and the measurement was made for each rhizome sample. Post- processing of the measured data was completed at the Department of Physics, Faculty of Science, Universiti Putra Malaysia.

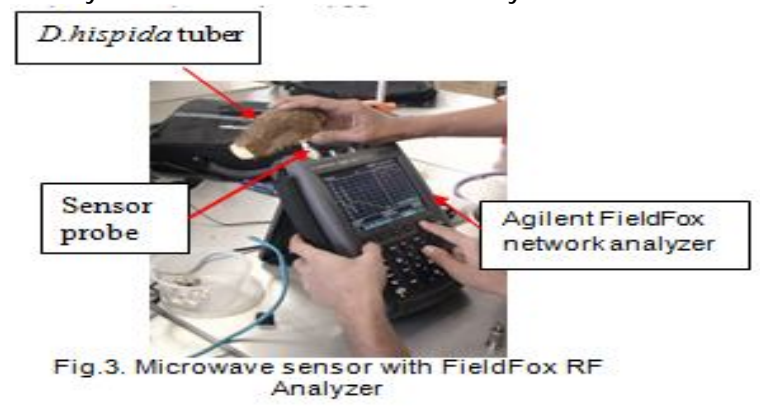

3.2 Chemical Experiment for Alkaloid Determination

The experimental method was adopted from the chemical analysis method (Megh and Jun ,2005).

After the rhizome was peeled, they were weighed (40 grams) and sliced. Each sample was blended with $200 \mathrm{~mL}$ of $0.5 \mathrm{M}$ $\mathrm{HCl}$ using an electric blender. For $\mathrm{HCl}$ preparation, $42 \mathrm{~mL}$ of ???HCl was dissolved with distill water (??? $\mathrm{mL}$ ).

The mixtures of sample were transfered into conical flask covered with parafilm and stand at room temperature for 2 days. After that, the samples were filtered using muslin cloth followed by filter paper; (Whatman Cat No 1001 150). The pH of the samples was checked using $\mathrm{pH}$ meter. The mixtures were made alkaline $(\mathrm{pH} 10-11)$ by adding $\mathrm{K}_{2} \mathrm{CO}_{3}$ and extracted with 3 portion $(600-200 \mathrm{mLI} \times 3)$ of ether using the separating funnel. All of the extracts were combined and dried overnight with $\mathrm{Na}_{2} \mathrm{SO}_{4}$. Dried extract was filtered and concentrated under reduced pressure using rotor evaporator. The concentrated extract was spotted on a $20 \times 20 \mathrm{~cm}$ TLC plate (Silica gel G, $60 \mathrm{~F}_{254}, 0.5$ $\mathrm{mm}$ thickness, Merck). The compounds were separated by an ascending method with a solvent mixture of chloroform:ethanol:ammonia (100:10:0.5). The plates were air-dried and were sprayed with Dragendorff reagent. The calculated $R_{f}$ value compared with literature $R_{f}$ value (Leete $E$ and Pinder [6]). Figure 4 show the process for alkaloid determination and Figure 5 shows the process flow.

Figure 6 show the relationship between the magnitude of the reflection coefficient of the sensor antenna probe and alkaloid content in the D.hispida rhizome samples. From the graph, the correlation square, R2 indicated 0.806 which mean that the magnitude of the reflection coefficient had strongly linear correlate with the alkaloid level of D.hispida.

3.3 Determination of relationship between magnitude of the reflection coefficient, $|\mathrm{S} 11|$ and percentage of dioscorine content

\section{RESULT AND CALCULATION}

With an assumption that the alkaloid content in the whole rhizome is homogeneous, results in table 1 were used to calculate weight percentage of alkaloid content using equation below:

$$
D C \%=\frac{m_{\text {alkoloid }}}{m_{\text {sample }}} \times 100 \%
$$

Table 2 show the percentage of alkaloid content and magnitude of reflection coefficient |S11| at $561.7 \mathrm{MHz}$ of every sample. The sample I and $\mathrm{b}$ indicated 2 plants of $D$. hispida. The symbols of ' $a, b, c$ ' indicated the different rhizome of tubers while '1,2,3' indicated the level of tuber from stem, 1 is the nearest with stem.

A large number of data was measured in $2 \mathrm{MHz}$ to $4 \mathrm{GHz}$ frequency range. A statistical approach was used to determine the optimal frequency which has the best correlation between percentage alkaloid content and magnitude of the reflection coefficient, |S11|. The optimal frequency was found to be 0.9076 at frequency $561.7 \mathrm{MHz}$.

\section{DISCUSSION}

Based on Figure 6 , the correlation between the magnitude of the reflection coefficient of the sensor antenna probe and alkaloid content in the D.hispida rhizome samples is high, 
with $\mathrm{R}^{2}=0.806$. This result means we can use this method and proceed to determine the relation between dioscorine content and the magnitude of the microwave sensor. This work is a nondestructive method, where the users only need to insert the sensor antenna probe to the rhizome.

We can use the mathematical equation, $y=1.289 x+0.276$, where $x=a$ alkaloid content $(\%)$ and $y=$ magnitude of the reflection coefficient (unitless) to find the amount of the alkaloid in the tested rhizome.

\section{CONCLUSION}

The model using the mathematical equation to predict the level of alkaloid of the D.hispida rhizome. Therefore, the amount of water needed to remove the toxic compound and the time consuming in the process can be determined.

\section{ACKNOWLEDGEMENT}

Greatest thank to the Al Mighty ALLAH who provided health and strength. The authors would like to thank the Unit Perancangan Ekonomi Negeri (UPEN) Terengganu, who provided fund for this project. Also to those who are directly and indirectly gave their support and help for the success of this project.

\section{REFFERENCES \\ [1] Abbas Z. (1994) A Microstrip Sensor for Determination of Harvesting Time for Oil Palm Fruits. MSc Thesis, Universiti Putra Malaysia. \\ [2] FAO (2011) Retrieved 22 February 2011 from http://www.fao.org. \\ [3] Hahn S.K., (1995) Yams:Dioscorea spp. (Dioscoreaceae). In: J. Smartt and N.W. Simmonds (Eds), Evolution of crop plants, pp:112-120. Longman Scientific and technical, UK. \\ [4] Mohd. Hudzari Hj Razali, Hasbullah Hj Muhammad, Noordin Asimi Mohd and Wan Ishak Wan Ismail (2011) Journal of Crop Science, 2(1): pp.21-26. \\ [5] Jill E.Wilson and Linda S.Hamilton (1988) A Practical Guide to Identifying Yams;The Main Species of Dioscorea in the Pacific Islands, Agro- Facts, Crops, IRETA Publication 1/88. \\ [6] Leete E., Pinder A.R. (1972) Phytochemistry 11: 3219-3224. \\ [7] Megh Raj Bhandari and Jun Kawabata (2005) Plant Foods for Human Nutrition 60:129-135 \\ [8] Nashriyah M., Nornasuha Y., Salmah T., Norhayati N. and Mohd. Rohaizad (2010) Buletin UniSZA, No. 4, ISSN 2180-0235. \\ [9] Sharifah (2011) Colloquium on Research Program for Dioscorea hispida (Ubi gadung), 16 February 2011, Kuala Terengganu, Malaysia \\ [10] Udensi E.A., Oselebe H.O., and Iweala O.O (2008) Pakistan Journal of Nutrition, 7(2): 324-344.}

[11] You K.Y. et al. (2010) Measurement Science Review, 10, 1 . 
Table 1 eight of alkaloid in 40 grams of rhizome

\begin{tabular}{|c|c|c|c|}
\hline SAMPLE & $\begin{array}{c}\text { WT EMPTY } \\
\text { FLASK(g) }\end{array}$ & $\begin{array}{c}\text { WT } \\
\text { FLASK+ALKALOID(g) }\end{array}$ & $\begin{array}{c}\text { WT } \\
\text { ALKALOID(g) }\end{array}$ \\
\hline I 1a & 103.966 & 104.016 & 0.05 \\
\hline I 1b & 89.7 & 89.783 & 0.083 \\
\hline I 2a & 93.818 & 93.86 & 0.042 \\
\hline I 2b & 98.058 & 98.071 & 0.013 \\
\hline I 2c & 93.943 & 94.035 & 0.092 \\
\hline B 1a & 160.951 & 161.023 & 0.072 \\
\hline B 1b & 92.726 & 92.843 & 0.117 \\
\hline B 1c & 31.228 & 31.271 & 0.043 \\
\hline B 2a & 88.777 & 88.826 & 0.049 \\
\hline B 2b & 88.86 & 88.945 & 0.085 \\
\hline B 3a & 88.495 & 88.619 & 0.124 \\
\hline B 3b & 159.602 & 159.695 & 0.093 \\
\hline & & & \\
\hline
\end{tabular}

Table 2- Percentage of alkaloid content and |S11| at $561.7 \mathrm{MHz}$ of every sample

\begin{tabular}{|c|c|c|}
\hline SAMPLE & WT ALKALOID $(\mathrm{g})$ & $|\mathrm{S} 11|$ \\
\hline I $1 \mathrm{a}$ & 0.050 & 0.446051 \\
\hline I $\mathrm{b}$ & 0.083 & 0.461079 \\
\hline I 2a & 0.042 & 0.356763 \\
\hline I $\mathrm{b}$ & 0.013 & 0.305805 \\
\hline I 2c & 0.092 & 0.529121 \\
\hline B 1a & 0.072 & 0.494567 \\
\hline B 1b & 0.117 & 0.676441 \\
\hline B 1c & 0.043 & 0.41735 \\
\hline B 2a & 0.049 & 0.491479 \\
\hline B 2b & 0.085 & 0.621828 \\
\hline B 3a & 0.124 & 0.614908 \\
\hline B 3b & 0.093 & 0.651231 \\
\hline
\end{tabular}




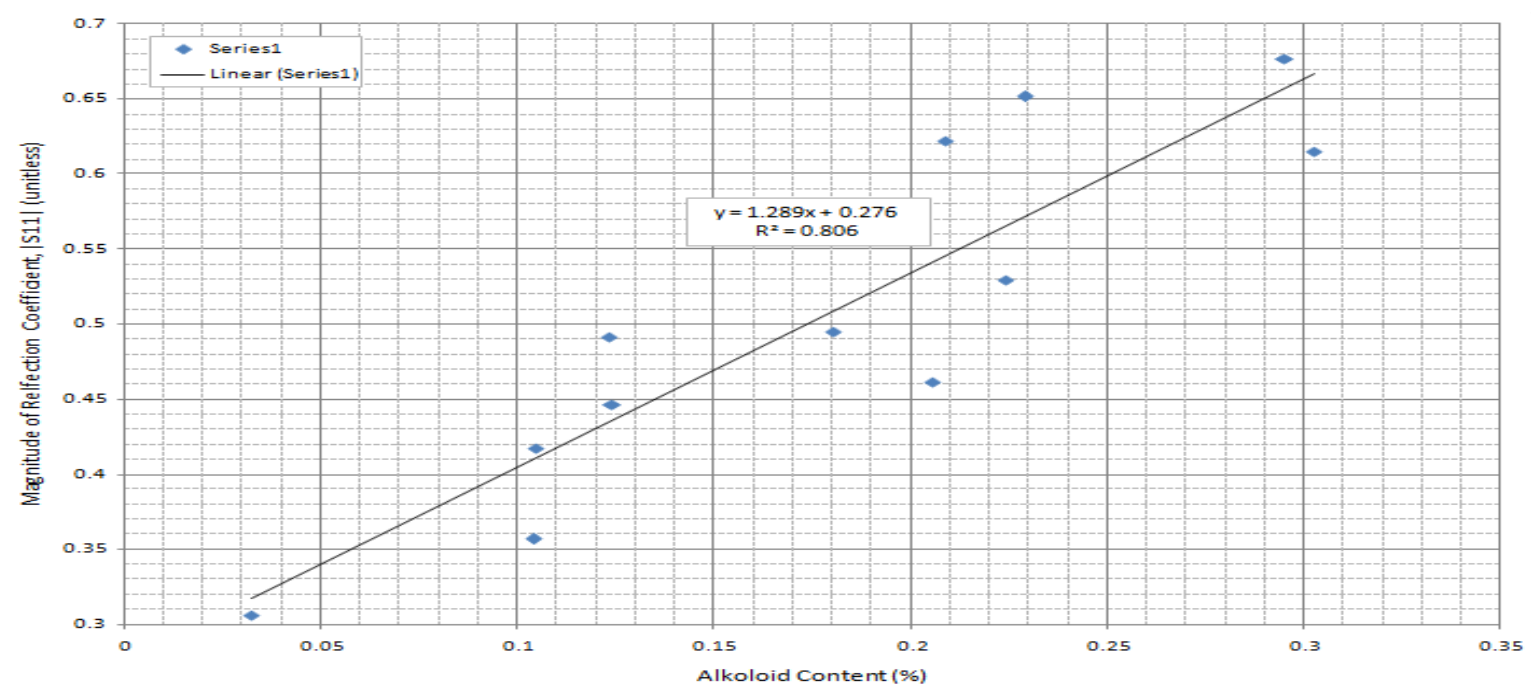

Fig.6. the relationship between the magnitude of the reflection coefficient of the sensor antenna probe and alkaloid content in the D.hispida rhizome samples

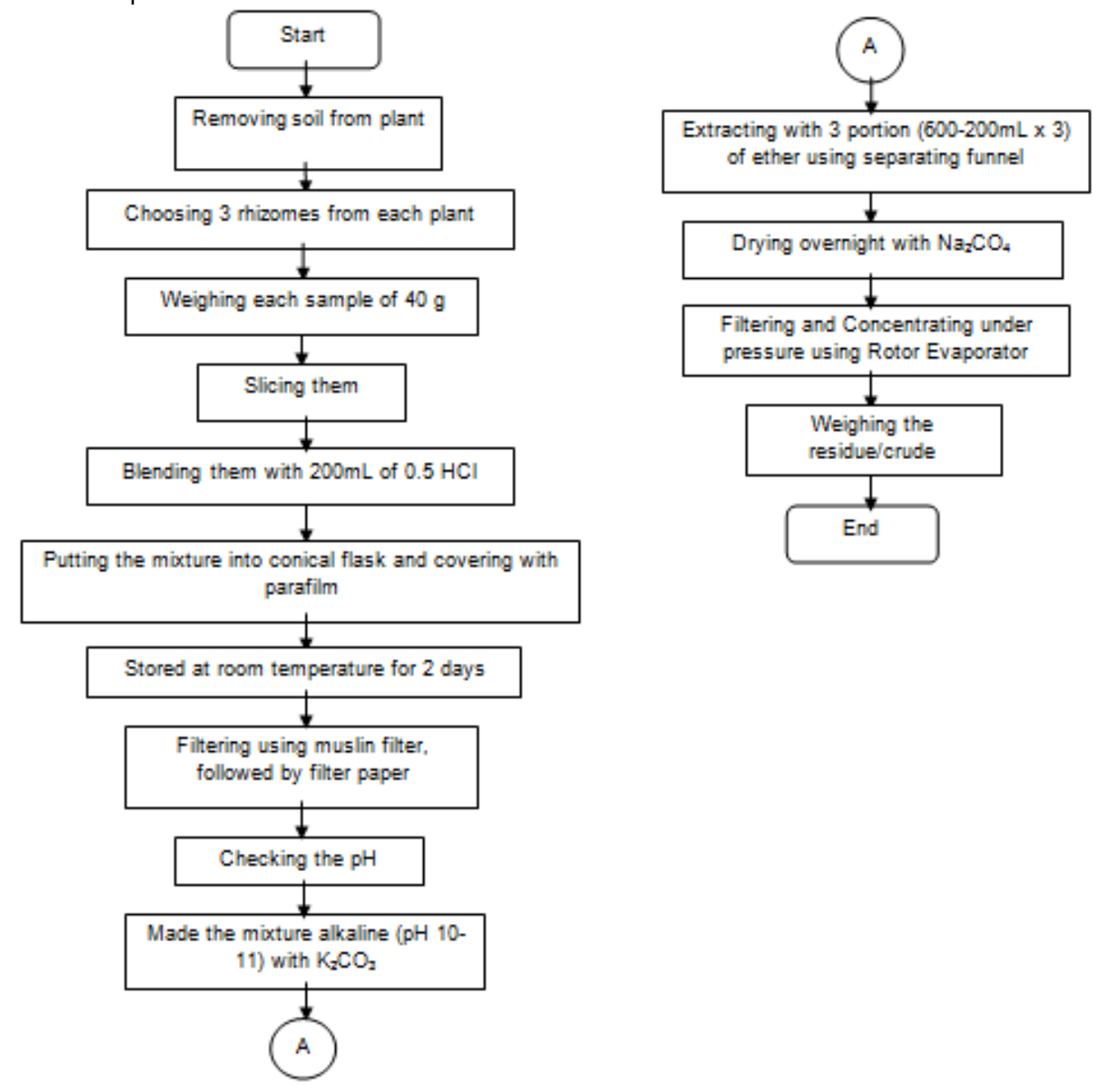

Fig.4. Process for alkaloid determination

International Journal of Machine Intelligence

ISSN: 0975-2927 \& E-ISSN: 0975-9166, Volume 3, Issue 5, 2011 

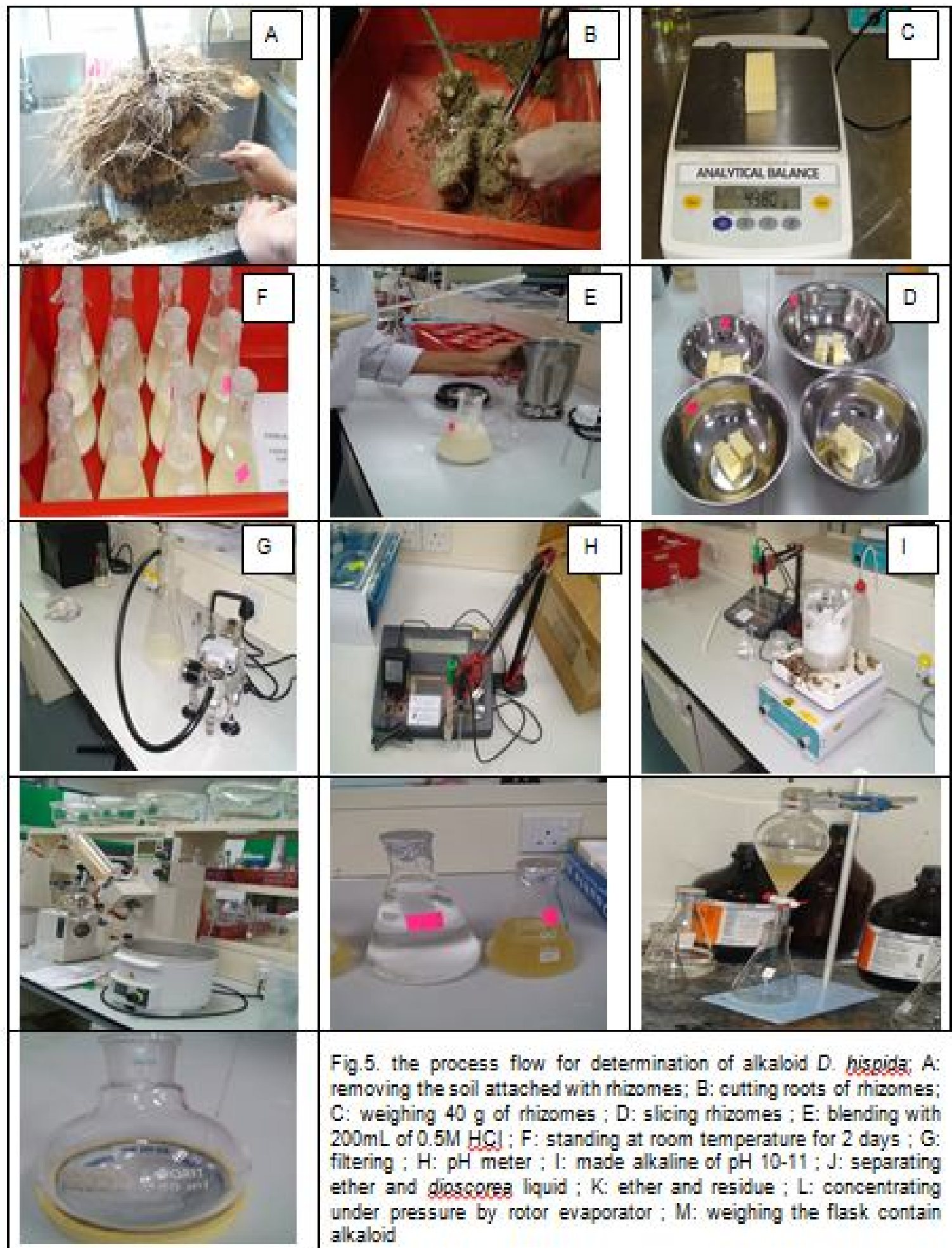

Fig.5. the process flow for determination of alkaloid D. hispida; $A$ : removing the soil attached with rhizomes; B: cutting roots of rhizomes; $\mathrm{C}$ : weighing $40 \mathrm{~g}$ of rhizomes ; D: slicing rhizomes ; E: blending with $200 \mathrm{~mL}$ of $0.5 \mathrm{M} \mathrm{HCl} ; \mathrm{F}$ : standing at room temperature for 2 days ; $G$ : filtering ; $\mathrm{H}$ : $\mathrm{pH}$ meter ; I: made alkaline of $\mathrm{pH} 10-11$; J: separating ether and giescores liquid ; $\mathrm{K}$ : ether and residue ; L: concentrating under pressure by rotor evaporator ; M: weighing the flask contain alkaloid 